\title{
PERANCANGAN POSTER DAN WADAH SAMPAH KARAKTER SEBAGAI MEDIA KAMPANYE PEDULI LINGKUNGAN SMP ISLAM AL MUSTARIH
}

\author{
Hamidah Apriani, Ida Rosida, M. Sjafei Andrijatno
}

Desain Komunikasi Visual, Fakultas Bahasa dan Seni, Universitas Indraprasta PGRI

\begin{abstract}
Abstrak
Sekolah adalah sebuah lembaga yang dirancang untuk pengajaran siswa atau murid di bawah pengawasan pendidik atau guru. Ketersediaan sarana pada suatu sekolah memiliki peranan penting dalam terlaksananya proses pendidikan. Salah satu fasilitas penunjang yang berkaitan dengan peduli lingkungan sekolah adalah ketersediaannya wadah sampah sebagai tempat yang dapat digunakan untuk membuang sampah atau barang-barang yang sudah tidak terpakai. Dalam hal ini, tentu diperlukan sikap kepedulian siswa untuk membuang sampah pada tempatnya. Media yang dapat mendukung usaha untuk meningkatkan rasa kepedulian siswa ialah melalui poster. SMP Islam Al Mustarih memiliki beberapa permasalahan yakni kurangnya media tentang kepedulian siswa terhadap lingkungan sekolah dan masih sedikitnya wadah sampah yang dimiliki oleh pihak mitra. Kami tim dosen dari Universitas Indraprasta PGRI Jakarta memberikan solusi berupa kampanye peduli lingkungan sekolah melalui media poster dan pembuatan wadah sampah dengan gambar yang berkarakter. Tujuan dari kegiatan pengabdian masyarakat ini adalah memberikan penyuluhan kepada siswa siswi SMP Islam Al Mustarih untuk menumbuhkan jiwa kepedulian terhadap lingkungan sekolah melalui poster dan pemberian gambar karakter untuk wadah sampah. Metode penelitian yang digunakan adalah metode kualitatif yaitu dengan mengumpulkan data berupa survei ke lokasi mitra, wawancara dan penyuluhan. Hasil dari penelitian ini adalah perancangan poster dan wadah sampah karakter yang dapat digunakan sebagai media kampanye peduli lingkungan sekolah.
\end{abstract}

Kata Kunci: poster, wadah sampah, kampanye

\begin{abstract}
A school is an institution designed for teaching students or students under the supervision of educators or teachers. The availability of facilities in a school has an important role in the implementation of the education process. One of the supporting facilities related to caring for the school environment is the availability of garbage containers as a place that can be used to dispose of waste or items that are not used. In this case, of course students need a caring attitude to dispose of garbage in its place. Media that can support efforts to increase students' awareness is through posters. SMP Islam Al Mustarih has several problems, namely the lack of media about student concern for the school environment and the lack of garbage containers owned by partners. Our team of lecturers from Indraprasta University PGRI Jakarta provided a solution in the form of a campaign to care about the school environment through poster media and the creation of trash containers with character images. The purpose of this community service activity is to provide counseling to students of SMP Islam Al Mustarih to foster a spirit of caring for the school environment through posters and giving character images to garbage containers. The research method used is a qualitative method by collecting data in the form of surveys to partner locations, interviews and counseling. The results of this study are the design of posters and character trash containers that can be used as campaign media to care about the school environment.
\end{abstract}

Keywords: posters, garbage containers, campaigns

Correspondence author: Hamidah Apriani, hamidahapriani09@gmail.com, Indonesia 


\section{PENDAHULUAN}

Sekolah adalah sebuah lembaga yang dirancang untuk pengajaran siswa atau murid di bawah pengawasan pendidik atau guru. Sebagian besar negara memiliki sistem pendidikan formal yang umumnya wajib dalam upaya menciptakan anak didik yang mengalami kemajuan setelah melalui proses pembelajaran. Menurut Sunarto pada saat ini kata sekolah telah berubah artinya menjadi bangunan atau lembaga untuk belajar dan mengajar serta tempat memberi dan menerima pelajaran.

Ketersediaan sarana pada suatu sekolah memiliki peranan penting dalam terlaksananya proses pendidikan. Salah satu fasilitas penunjang yang berkaitan dengan peduli lingkungan sekolah adalah ketersediaannya wadah sampah sebagai tempat yang dapat digunakan untuk membuang sampah atau barang-barang yang sudah tidak terpakai. Dalam hal ini, tentu diperlukan sikap kepedulian siswa untuk membuang sampah pada tempatnya. Kepedulian terhadap lingkungan bermanfaat akan berkisinambungannya alam dan kehidupan manusia. Dengan mencintai lingkungan sejak dini, maka kehidupan akan lebih sehat.

Media yang dapat mendukung usaha untuk meningkatkan rasa kepedulian siswa ialah melalui poster. Pada dasarnya sebuah poster dibuat dengan tujuan menarik perhatian banyak orang agar berpartisipasi memenuhi imbauan yang disampaikan dalam poster tersebut. Dalam hal ini, siswa-siswa agar lebih tertarik dalam menjaga kebersihan lingkungan sekolah.

Menurut Sudjana dan Rivai, poster adalah kombinasi visual dari rancangan yang kuat dengan warna dan pesan dengan maksud untuk menangkap perhatian orang yang lewat tetapi cukup lama menanamkan gagasan yang berarti dalam ingatannya. Jika ingin menarik perhatian dan mempunyai pengaruh yang cukup kuat dalam menyampaikan pesan, poster haruslah memiliki daya tarik pandang yang kuat. Untuk itu dalam mendesain poster haruslah mematuhi karakteristik poster.

Dalam membuat poster yang menarik, tentu saja membutuhkan keterampilan menulis yang baik. Sebagaimana pendapat yang dikemukakan Tarigan (2008:22), menulis ialah menurunkan atau melukiskan lambang-lambang grafik yang menggambarkan suatu bahasa yang dipahami oleh seseorang, sehingga orang-orang lain dapat membaca lambang-lambang grafik tersebut kalau mereka memahami bahasa dan gambaran grafik tersebut. Keterampilan menulis ini tidak akan datang secara otomatis, tetapi harus melalui latihan dan praktik yang banyak dan teratur (Tarigan 2008:3-4). Dengan demikian dapat disimpulkan bahwa kemampuan menulis menjadi salah satu faktor pembuatan poster yang bagus dan menarik.

Poster yang digunakan dalam kegiatan ini berbentuk larangan dan peringatan. Poster ini bertujuan untuk menginformasikan mengenai apa yang tidak boleh dikerjakan atau dilarang. Poster ini juga menginformasikan agar audiens mengikuti ajakan atau larangan. Sebagai contoh "Buanglah Sampah Pada Tempatnya".

SMP Islam Al Mustarih adalah sekolah menengah pertama yang berdiri pada tahun 1978, terletak di Jl. Cibalagung No.III Pasir Kuda, Bogor Barat. Jika dilihat dari situasi dan kondisi berdasarkan survei kami tim Pengabdian Masyarakat Universitas Indraprasta PGRI, terdapat dua permasalahan mitra yakni:

1. kurangnya media tentang kepedulian siswa terhadap lingkungan sekolah.

2. masih sedikitnya wadah sampah yang dimiliki oleh pihak mitra.

Melihat kondisi tersebut maka perlu adanya media yang menarik bagi siswa agar dapat meningkatkan rasa kepeduliannya terhadap lingkungan sekolah yaitu dengan 
poster. Selain itu, perlu adanya wadah sampah dengan gambar ilustrasi berkarakter dengan penambahan kata-kata ajakan untuk peduli terhadap lingkungan.

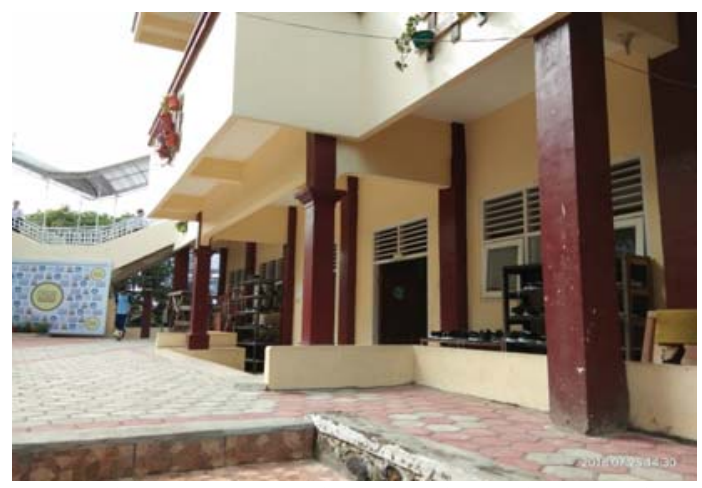

Gambar 1. Suasana di SMP Islam Al Mustarih

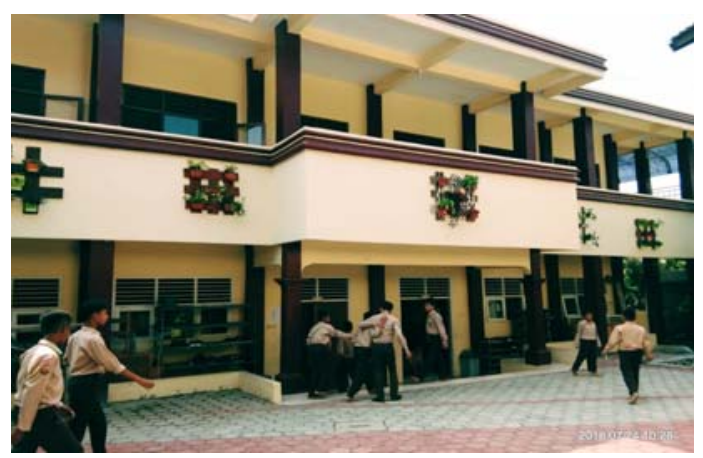

Gambar 2. Bagian Tengah SMP Islam Al Mustarih

Dengan melihat permasalahan yang ada, Kami Tim Pengabdian Masyarakat Universitas Indraprasta PGRI memberikan solusi berupa perancangan poster dan wadah sampah karakter sebagai kampanye peduli lingkungan sekolah.

Poster sebagai media informasi agar siswa peduli terhadap kebersihan lingkungan sekolah. Sehingga siswa akan selalu mengingat untuk membuang sampah pada tempatnya. Sementara wadah sampah berkarakter bertujuan untuk membuat perhatian siswa di lingkungan SMP Islam Al Mustarih agar dapat memiliki kesadaran untuk menciptakan sekolah yang bersih, nyaman, dan indah.

Tujuan dari kegiatan abdimas adalah memberikan penyuluhan kepada siswa siswi dan beberapa guru SMP Islam Al Mustarih untuk menumbuhkan jiwa kepedulian terhadap lingkungan sekolah melalui poster dan pemberian gambar karakter untuk wadah sampah. Hasil karya yang dihasilkan berupa sebuah poster dan wadah sampah karakter. Dengan penyuluhan melalui poster sebagai media kampanye ini diharapkan siswa memiliki ketertarikan dalam menciptakan kebersihan lingkungan sekolah.

Manfaat kegiatan pengabdian masyarakat yang dilaksanakan di SMP Islam Al Mustarih adalah:

1. Memberikan informasi dalam bentuk poster sebagai media kampanye peduli lingkungan sekolah.

2. Menciptakan lingkungan sekolah yang nyaman, bersih, dan sehat sebagai bentuk rasa kepedulian siswa.

3. Memberikan wadah sampah berkarakter sebagai sarana untuk menunjang kebersihan lingkungan sekolah. 


\section{METODE PELAKSANAAN}

Tujuan dari kegiatan abdimas adalah untuk memberikan penyuluhan yang menarik tentang poster dan wadah sampah karakter sebagai media kampanye untuk meningkatkan rasa kepedulian siswa akan kebersihan lingkungan sekolah. Dengan pelatihan ini diharapkan poster dan pemberian wadah sampah karakter dijadikan sebagai sarana penunjang dalam menggugah kesadaran siswa siswi SMP Islam Al Mustarih dalam menciptakan kebersihan sekolah.

Target dalam arti sasaran pengabdian masyarakat adalah kurang lebih sepuluh siswa dan siswi dan beberapa guru SMP Islam Al Mustarih. Target dalam arti pencapaian yang dicanangkan dalam pengabdian masyarakat ini, bahwa setelah mengikuti kegiatan ini, diharapakan dapat:

1. memberikan pengetahuan umum mengenai peduli terhadap lingkungan sekolah melalui media poster bagi pihak guru di SMP Islam Al Mustarih khususnya, sehingga implementasi tersebut juga bisa disampaikan kepada siswa dalam bentuk wadah sampah berkarakter,

2. memberikan kemudahan bagi guru dalam proses penyuluhan yaitu dengan memanfaatkan wadah sampah yang diberikan ilustrasi karakter,

3. meningkatkan wawasan dalam penerapan wadah sampah berkarakter, sehingga kepedulian lingkungan bisa dimulai dari sekolah,

4. meningkatan rasa kepedulian siswa terhadap lingkungan sekolah agar tercipta sekolah yang bersih, nyaman, dan indah.

Adapun luaran (output) Pengabdian Masyarakat ini adalah dalam bentuk sebuah poster dan 2 wadah sampah karakter. Siswa siswi dan beberapa guru yang terlibat dalam kegiatan ini akan kami dokumentasikan sebagai arsip lalu kami masukkan dalam laporan. Untuk publikasinya kami masukkan laporan kegiatan Pengabdian Masyarakat ini dalam bentuk Jurnal.

Proses pelaksanaan kegiatan Pengabdian kepada Masyarakat dilaksanakan selama 5 (lima) bulan, yaitu dimulai 15 September 2018 sampai dengan bulan Desember 2018. Pelaksanaan diawali dengan observasi dan wawancara di SMP Islam Al Mustarih, kemudian dilanjutkan dengan menyusun materi pelatihan. Dalam Kegiatan ini, metode pelaksanaan dibagi lima tahap, yaitu:

1. Tim melakukan observasi dan wawancara untuk mengetahui apa yang dibutuhkan oleh SMP Islam Al Mustarih.

2. Hasil dari tahap observasi, kemudian dijadikan bahan pertimbangan untuk memberikan kemudahan bagi guru dalam proses penyuluhan yaitu dengan memanfaatkan wadah sampah yang diberikan ilustrasi karakter.

3. Tahap selanjutnya kami mempersiapkan peralatan dan perlengkapan yang dibutuhkan untuk kampanye peduli lingkungan sekolah melalui poster dan penempelan gambar karakter untuk wadah sampah.

4. Di dalam tahap penyuluhan, diawal kami memberikan penjelasan mengenai poster dan makna gambar karakter yang digunakan untuk wadah sampah, yaitu perbedaan sampah organik dan anorganik.

5. Pada penyuluhan tersebut, para siswa siswi SMP Islam Al Mustarih mencoba menempelkan gambar karakter di wadah sampah yang sesuai dengan fungsinya yaitu sampah organik dan sampah anorganik mengikuti tahapan yang sudah dijelaskan. 


\section{HASIL DAN PEMBAHASAN}

Pelatihan abdimas perancangan poster dan wadah sampah karakter diawali memberikan penjelasan kepada peserta mengenai pentingnya memiliki rasa kepedulian terhadap lingkungan sekolah juga penjelasan tentang sampah organik dan anorganik kepada siswa siswi SMP Islam Al Mustarih.

Langkah-langkah dan teknis abdimas yaitu:

1. Penjelasan tentang gambar karakter untuk wadah sampah organik dan sampah anorganik.

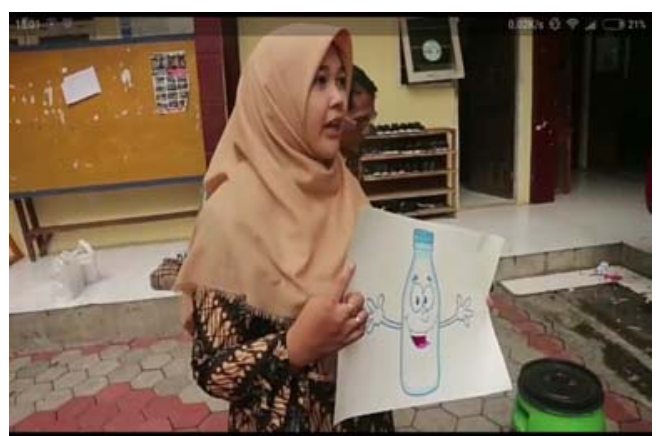

Gambar 3. Penjelasan materi tentang sampah

2. Pembuatan poster dengan tema lingkungan hidup. Pesan dalam poster yang disampaikan menggunakan bahasa yang lugas, mudah dibaca, mudah diingat dan mudah dipahami oleh audiens.

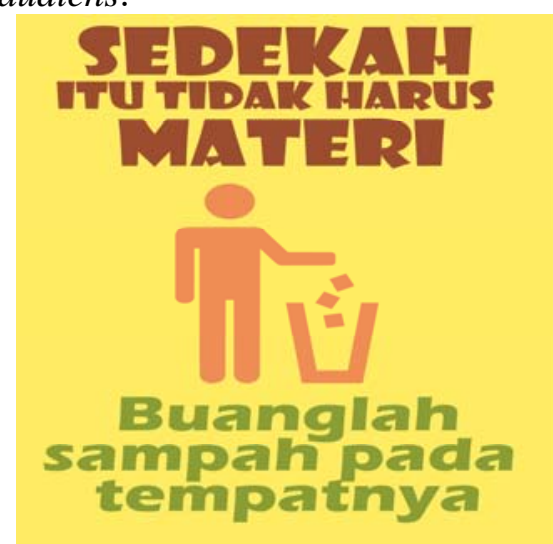

Gambar 4. Desain Poster

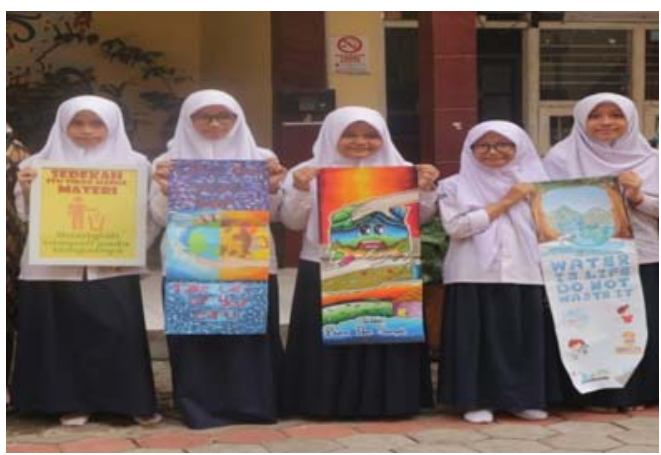

Gambar 5. Hasil Karya Siswa Membuat Poster 
3. Membuat konsep desain sampah karakter yaitu berupa sketsa pemilihan gambar atau ilustrasi dan warna disesuaikan dengan karakter sampah organik dan sampah anorganik.
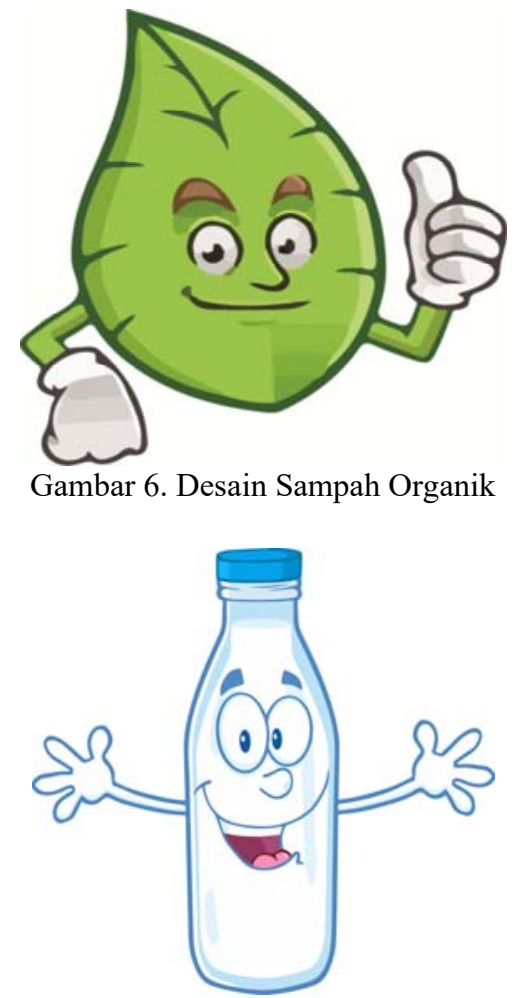

Gambar 7. Desain Sampah Anorganik

4. Proses pengguntingan dan penempelan stiker gambar karakter untuk wadah sampah.

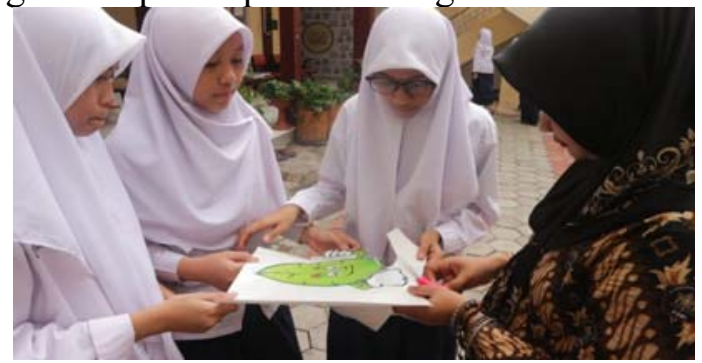

Gambar 8. Proses pengguntingan stiker 


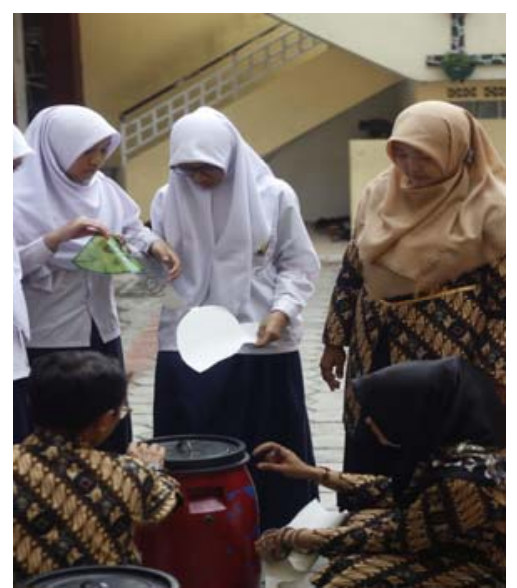

Gambar 9. Proses Penempelan Stiker

5. Hasil Kampanye Peduli Lingkungan Sekolah

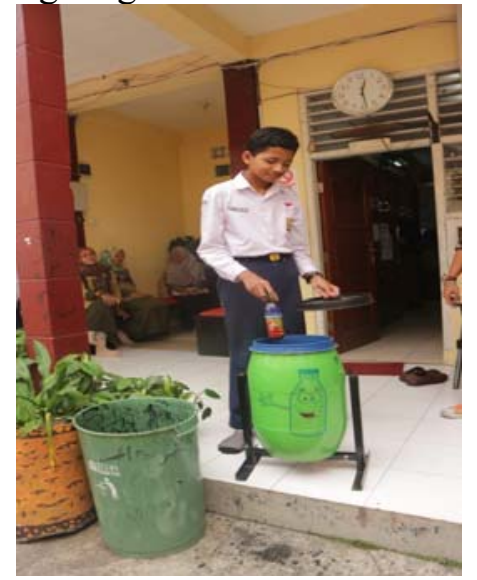

Gambar 10. Kampanye Peduli Lingkungan Sekolah

6. Apresiasi karya dengan kepala sekolah, guru-guru dan siswa siswi SMP Islam Al Mustarih.

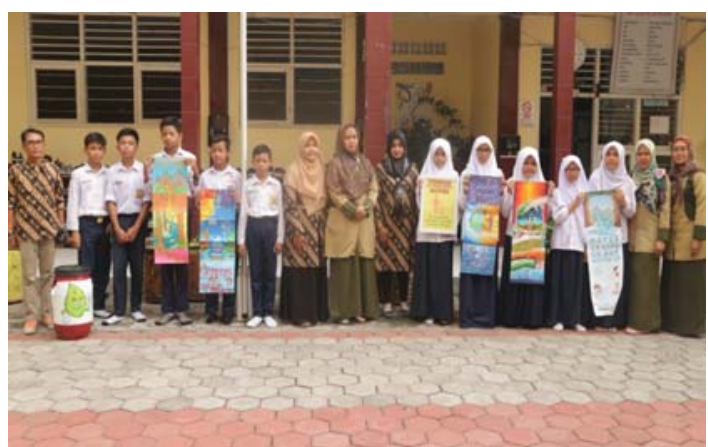

Gambar 11. Foto Bersama Siswa Siswi dan Kepala Sekolah SMP Islam Al Mustarih

Dalam kegiatan Pengabdian Masyarakat Perancangan Poster dan Wadah Sampah Sebagai Media Kampanye Peduli Lingkungan Sekolah di SMP Islam Al Mustarih, memberikan simpulan bahwa kegiatan ini: 
1. Penyuluhan dalam kampanye peduli lingkungan sekolah berjalan dengan baik. Siswa siswi SMP Islam Al Mustarih sangat antusias memerhatikan dan mencoba praktik langsung dalam pembuatan poster tentang peduli lingkungan.

2. Dalam praktik langsung membuat desain poster semua sudah berjalan dengan lancer. Hasil praktik langsung peserta yang bagus dalam membuat desain poster kami persilahkan untuk dipasang di tembok sekolah SMP Islam Al Mustarih dan kami berikan sebagai kenangan dari kami.

3. Tim Dosen memberikan sebuah poster peduli lingkungan sekolah yang telah dibingkai untuk dipasang di tembok sekolah dan wadah sampah karakter sebagai hasil penyuluhan agar dapat dimanfaatkan di sekolah.

\section{SIMPULAN}

Kebersihan dalam lingkungan sekolah merupakan hal yang sangat penting diwujudkan. Dengan lingkungan sekolah yang bersih maka akan tercipta suasana belajar yang nyaman dan sehat juga kegiatan-kegiatan lain akan berlangsung dengan baik. Mewujudkan lingkungan sekolah yang bersih tentu berkaitan dengan rasa kepedulian siswa terhadap hal tersebut. Solusi berupa perancangan desain poster dan wadah sampah karakter menjadi salah satu cara yang tepat dalam kampanye untuk meningkatkan rasa kepedulian siswa terhadap lingkungan sekolah. Karena poster yang menarik dan wadah sampah karakter merupakan media yang efektif sebagai media penunjang untuk meningkatkan rasa kepedulian siswa terhadap lingkungan sekolah yang bersih, indah, dan sehat.

\section{DAFTAR PUSTAKA}

Ahmadi. A dan Sholeh. M. (2005). Psikologi Perkembangan. Jakarta: Rineka Cipta.

Idi, A. (2011). Sosiologi Pendidikan (Individu, Masyarakat, dan Pendidikan). Jakarta: PT Raja Grafindo Persada.

Sudjana, N. dan Rivai, A.. (1990). Media Pengajaran. Bandung: Citra Aditya Bakti.

Supriyono, R.. (2010). Desain Komunikasi Visual (Teori dan Aplikasi). Yogyakarta: Penerbit ANDI Yogyakarta.

Tarigan, H. G. (2008). Menulis (Sebagai Suatu Keterampilan Berbahasa). Bandung: Angkasa.

http://dilihatya.com/986/pengertian-poster-menurut-para-ahli 